\title{
Retraction Note to: A Study on Email Security Through Cryptographic Techniques
}

\author{
Akhilesh Kumar Singh ${ }^{(\bowtie)}$, Vinesh Kumar, and Sharad Pratap Singh \\ GLAU, Mathura, UP, India \\ \{akhileshkr. singh, vinesh. kumar, \\ sharad.singh\}@gla.ac.in
}

\section{Retraction Note to: \\ Chapter "A Study on Email Security Through Cryptographic Techniques" in: S. Smys et al. (Eds.): ICCNCT 2019, LNDECT 44, pp. 342-348, 2020. https://doi.org/10.1007/978-3-030-37051-0_40}

The editors have retracted this chapter "Singh A.K., Kumar V., Singh S.P. (2020) A Study on Email Security Through Cryptographic Techniques. In: Smys S., Senjyu T., Lafata P. (eds) Second International Conference on Computer Networks and Communication Technologies. ICCNCT 2019. Lecture Notes on Data Engineering and Communications Technologies, vol 44. Springer, Cham (https://doi.org/10.1007/9783-030-37051-0_40)" because it reports research undertaken by Shafiya Afzal Sheikh and M. Tariq Banday. A K Singh agrees to this retraction, and V Kumar and S P Singh have not responded to any correspondence from the editor/publisher about this retraction. 